\title{
Are there findings on MRI or on patient-reported back pain before surgery for lumbar disc herniation that can predict future progression of painful disc degeneration?
}

\author{
Oscar Solmell ${ }^{1}$, Patrick Dahlemar Sterner ${ }^{1}$ and Svante Berg ${ }^{2 *}$ \\ ${ }^{1}$ Medical School, Faculty of Medicine, Lund University, Lund, Sweden \\ ${ }^{2}$ Stockholm Spine Center and Karolinska Institute, Stockholm, Sweden
}

\begin{abstract}
Purpose: Low back pain (LBP) affects $50-85 \%$ of adults during their lifetime. It is sometimes caused by lumbar disc herniation (LDH), which will occasionally require surgery. Some patients operated for LDH are at risk of developing chronic low back pain (CLBP) caused by degenerative disc disease (DDD). This study aimed to determine if findings seen on preoperative magnetic resonance (MR) images or pain-scores can help identify these patients.
\end{abstract}

Methods: MR images from 851 patients, operated for LDH between 2002 and 2008, were studied concerning Modic changes, disc height and the location of LDH. Baseline data, acquired from SweSpine, and radiologic findings were statistically evaluated.

Results: Patients with Modic 2 scored lower on VAS for back pain than others ( $\mathrm{p}=0.036$ ). Patients who developed DDD showed a higher preoperative score for VAS back than patients who did not ( $\mathrm{p}=0,002)$. Although not statistically significant, M1 findings were more common among those who developed DDD, whereas M2 findings were more common in patients who did not develop DDD.

Conclusions: Our results imply that M2 seen on MR images before surgery for LDH and a low score for VAS back might indicate a lower risk of developing CLBP caused by DDD. A high score for VAS back was significantly more common among patients who developed DDD and more common among patients expressing M1, although not significantly. We also suggest a convincing, but not conclusive, correlation between M1, DD and the development of DDD that requires further research.

\section{Introduction}

Low back pain (LBP) is a costly and difficult diagnostic and therapeutic challenge. It affects approximately $50-85 \%$ of adults during their lifetime [1,2]. Symptoms are often mild and usually the patient recovers within 6 weeks [1]. If the pain lasts for more than 3 months, it is defined as chronic low back pain (CLBP). This condition affects approximately $8-24 \%$ of patients with LBP $[1,3]$. Patients recovering from their LBP within 6 weeks are at low risk for developing CLBP, but improvement seems to slow markedly after this time [4,5]. Smokers, patients with a relatively high baseline pain intensity, persistent neurologic signs (such as sciatica), a perception that their back pain will last a long time and/or patients with psychologic problems such as depression when LBP symptoms start are more prone to develop CLBP [2,4-6]. Although the underlying pathology of LBP remains unknown in most cases, the primary cause is believed to be degeneration of intervertebral discs $[7,8]$. Disc degeneration (DD) is a natural part of aging and in some individuals can be accelerated and progress into a chronic painful condition, usually called degenerative disc disease (DDD) [9]. Accelerated DD cannot be attributed to load, such as any specific profession. It is clearly established that DDD has a strong genetic component $[7,10]$ and smokers might be at greater risk [11]. Degenerative changes are often visible on radiologic examination, especially on magnetic resonance imaging (MRI). They can either be asymptomatic or symptomatic with pain and deteriorated function [12]. When lumbar DD turns symptomatic, it can manifest as either CLBP or sciatica as a result of lumbar disc herniation (LDH), or a combination of these. DDD is the main cause of CLBP and is best described as a mechanical lumbar pain condition in which specific motion and load trigger pain [8]. The reason, in most cases, is biochemical changes in the intervertebral disc $[8,13]$. The pain might also emanate from the facet joints or the ligaments in the lumbar region. A loss of disc height might generate a mismatch of the facet joints or a ligamentous laxity that in turn gives rise to painful arthritis $[9,12,13]$. All patients who develop CLBP because of DDD have by definition degenerative changes of the intervertebral disc $[12,13]$. Therefore, it is not uncommon that these patients also have, or have previously had, a disc herniation from the same degenerated disc [14].

\section{Radiological background}

Two studies that were published in 1988 are generally accepted

Correspondence to: Svante Berg, Stockholm Spine Center, Löwenströmska Sjukhuset, 19489 Upplands Väsby, Sweden, Tel: 460850902700; Fax: 460850902810; E-mail: svante.berg@spinecenter.se

Key words: degenerative disc disease, lumbar disc herniation, mri-findings, modic changes, chronic low back pain

Received: October 16, 2016; Accepted: November 02, 2016; Published: November 04, 2016 
today for defining degenerative vertebral body marrow changes (Modic changes) with MRI $[15,16]$. Modic change type 1 (M1) represents bone marrow oedema, seen as a hypo-intense signal on T1-weighted images (T1WI) and as a hyper-intense signal on T2-weighted images (T2WI). M2 reflects fat accumulation in the vertebral body seen as a hyper-intense signal on T1WI and as an iso- or hyper-intense signal on T2W1. M3, sclerosis, is seen as a hypo-intense signal on both T1WI and T2WI. The relationship between the types of Modic changes seems to be time dependent. An M1 can convert, fully or partly, into an M2 over time, be more prominent or can regress [15-17]. Furthermore, some M2 convert to M3 over time but it is more common that an M2 remains stable [15]. It seems that M1 reflects a more acute stage, M2 a more intermediate to chronic stage, and M3 the end stage of the same degenerative process [15-17]. Several published studies conclude that there is a connection between LBP, its severity and Modic changes [17-20]. M1 seems to correlate with more pain and accelerated DD $[17,19]$. LBP symptoms will improve over time in patients with M1 that develops into an M2 [17,19]. The absence of M1 indicates a slower degenerative process in line with normal aging [19]. On the other hand, another study suggests that there remains uncertainty about the association of MRI findings, LBP and CLBP [21].

\section{Methods}

The aim of this study was to investigate if it was possible to find predictors for patients at risk of developing DDD after LDH surgery. If predictors could be found, such as preoperative MRI findings, patient expectations could be addressed and clinicians could justify intensified and prolonged rehabilitation programs in an effort to avoid future CLBP and more extensive surgery [4-6].

\section{Inclusion and exclusion criteria}

Patients operated for LDH from the start of 2002 until the end of 2008 at Stockholm Spine Center were included. Exclusion criteria were previous spine surgery, other types of procedures than pure discectomy and lack of baseline data before surgical treatment (Figure 1).

\section{Data collection}

SweSpine, the Swedish Spine Register, is partly based on baseline questionnaires (including data on work status, smoking habits, age, gender, function and quality of life scores and visual analogue scale (VAS) for back and leg pain) completed by patients before spine surgery. The register currently includes approximately 100,000 patients.

Preoperative baseline data for all patients fulfilling the primary inclusion criteria were extracted from SweSpine; 1645 patients were included primarily but 238 patients were excluded because they were not being treated solely with removal of herniation, and 102 patients were excluded because of a lack of baseline data; 156 patients who had undergone previous lumbar spine surgery were excluded. Thus, 1149 patients were included in the study. Preoperative MR images from 844 patients were available for study. Seven of the patients had been operated on two lumbar segments at the same surgery. These two segments were analysed separately, resulting in 851 participants included in the MRI study (Figure 1).

\section{Radiologic analysis}

MR images were studied regarding the location of disc hernia, disc height, and the presence of Modic changes. The MR protocol consisted of sagittal and axial T1 and T2 sequences. Contrast was not used. Only the affected segments, addressed with discectomy, were examined. In

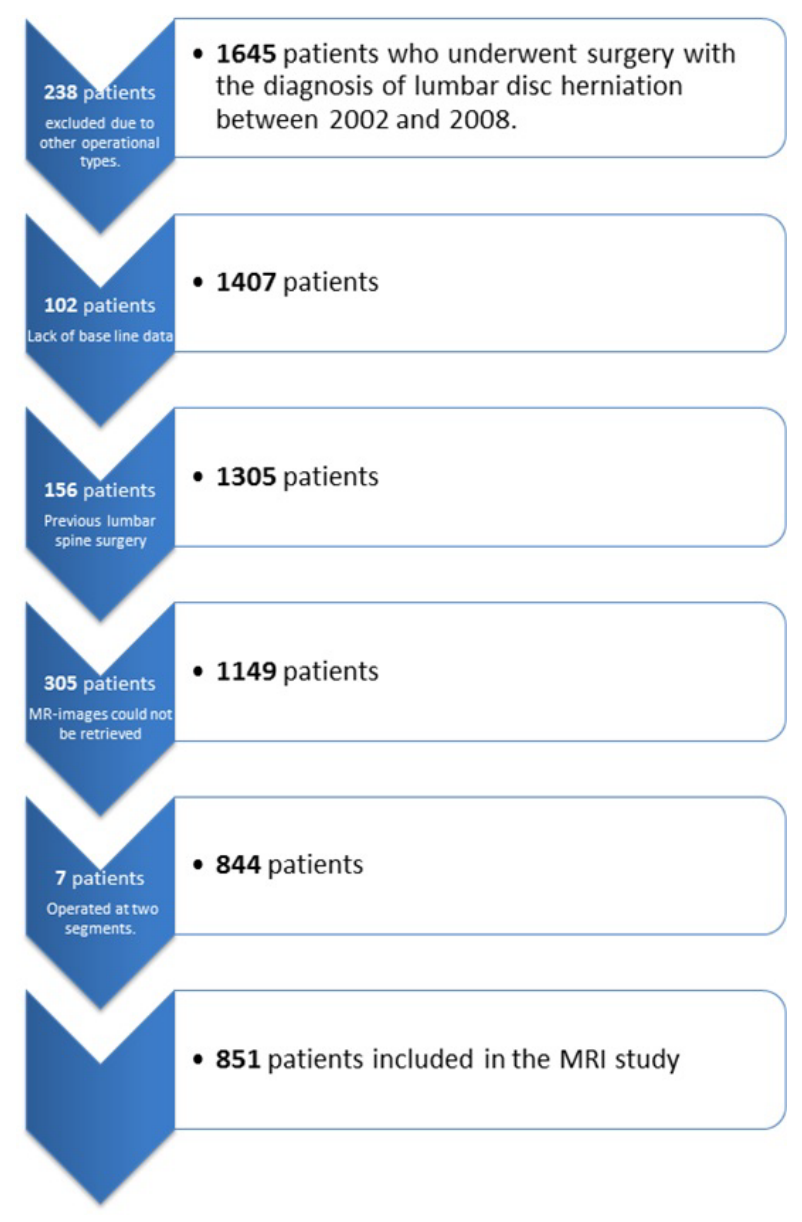

Figure 1. Flowchart illustrating the exclusion of the studied material.

line with earlier studies [22,23], the evaluation of disc height was based on the supposed disc height in the affected segment. For example, the L5-S1 disc is normally lower than the L4-L5 disc, which is normally higher or at least as high as the lumbar discs above [22,23]. The evaluation of disc height was based on the following questions:

1. Does the disc height seem to be normal? (1)

2. Does the disc height seem to be lower than normal, but not lower than $50 \%$ of its supposed height? (2)

3. Does the disc height seem to be markedly lower than normal, being less than $50 \%$ of its supposed height? (3)

The location of LDH was estimated to be medial (1) (not affecting the exiting nerve roots), paramedial (2) (not reaching beyond the lateral recess or into the foramina) or lateral (3) (foraminal or extraforaminal).

The evaluation of Modic changes was made according to the original definitions made by Modic et al. $[15,16]$. In addition, it was also noted if a patient showed more than one Modic type. Modic changes were classified as shown in Table 1. A medical student, who had several educational meetings with a specialist in neuroradiology, analysed the MR images. After the study, an inter-observer analysis was carried out. A radiologist rescanned the MR images from 87 patients (around $10 \%$ of the material). In addition, the student made an intra-observer analysis in which 100 of the patients' MRI scans were randomly chosen and re-examined. Kappa scores were calculated. After the radiologic study, a statistical analysis was made. Among the 851 patients, there 
Solmell O (2016) Are there findings on MRI or on patient-reported back pain before surgery for lumbar disc herniation that can predict future progression of painful disc degeneration?

Table 1. Classification of Modic types.

\begin{tabular}{|l|l|}
\hline M0 & No Modic change \\
\hline M1 & Modic change type 1 \\
\hline M1-2 & Modic change type 1 and Modic change type 2 \\
\hline M2 & Modic change type 2 \\
\hline M2-3 & Modic change type 2 and Modic change type 3 \\
\hline M3 & Modic change type 3 \\
\hline M1-3 & Modic change type 1 and Modic change type 3 \\
\hline M1-2-3 & Modic change type 1, Modic change type 2 and Modic change type 3 \\
\hline
\end{tabular}

were 58 patients who had developed DDD requiring surgical treatment between 2002 and 2013. The time interval was chosen to allow 5 years follow-up since the last LDH surgeries. The study was approved by the ethical committee of Karolinska Institute (KI-2013/224531/1). Patients who were surgically treated with either fusion or disc replacement because of CLBP after previous LDH surgery were defined as having developed DDD (DDD group), whereas patients who did not receive this added treatment were defined as not having developed DDD (non-DDD group).

\section{Statistical analysis}

Descriptive statistics were analysed. Differences in proportions concerning categorical data (Modic type, smoking and gender) were tested using the $\chi^{2}$ or Fisher exact test (frequencies $<5$ ). The numerical data (VAS back, VAS leg and age) were tested with a non-parametric Mann-Whitney test. Ninety-five percent confidence intervals were used. A multiple regression analysis was carried out. Variables were selected based on the descriptive and univariate analyses as well as clinical experience. In the multivariate and univariate analyses, the odds ratio with a 95\% confidence interval and an $R^{2}$ value (Cox and Snell or Nagelkerke) were calculated. Statistical analysis was made using Statistica version 13 (StatSoft Inc. Tulsa, OK, USA).

\section{Results}

\section{Descriptive analyses}

There were no significant correlations between the presence of any Modic change(s), the location of $\mathrm{LDH}$, disc height, age or gender and the development of DDD. Patients in the DDD group had higher scores for VAS back preoperatively (mean 48) than patients in the nonDDD group (mean 36) $(p=0.002)$ (Table 2, Figure 2).

\section{Modic changes}

In the DDD group, $25.9 \%$ showed M1. In the non-DDD group, $20.3 \%$ showed M1 ( $p=0.313)$. Furthermore, M2 was under-represented in the DDD group (32.8\%) compared with the non-DDD group $(40.0 \%)$, although not statistically significant $(p=0.278)$. No statistically significant results concerning M3 and the development of DDD were found. The correlation between DDD and Modic changes of any kind (M1 and/or M2 and/or M3) was also tested without any significant results. In the M2 group, the median VAS back score was 28 compared with 34 in the M0 group ( $p=0.036)$. M1 was more common among women and among smokers; $16.3 \%$ of the males and $27.9 \%$ of the females showed M1 $(p=0.000)$. Among smokers, $28.2 \%$ showed M1 compared with $19.2 \%$ among non-smokers $(p=0.013)$ (Tables 3 and 4 ).

\section{Disc height}

Among patients with a normal disc height (290 of 851 patients), $13.8 \%$ showed M1, $26.6 \%$ showed M2 and $3.4 \%$ had M1-2 ( $p=0.000)$. Of the 561 patients with a reduced disc height (disc height 2 or 3), $24.2 \%$
Table 2. Differences between the DDD group (1) and the non-DDD group (0).

\begin{tabular}{|c|c|c|c|}
\hline & \multicolumn{2}{|r|}{ DDD } & \multirow{2}{*}{ Test ( $p$ value) } \\
\hline & $0(\%)$ & $1(\%)$ & \\
\hline \multicolumn{4}{|l|}{ Modic 1} \\
\hline 0 & 79.7 & 74.1 & 0.313 \\
\hline 1 & 20.3 & 25.9 & \\
\hline \multicolumn{4}{|l|}{ Modic 2} \\
\hline 0 & 60 & 67.2 & \\
\hline 1 & 40 & 32.8 & 0.278 \\
\hline \multicolumn{4}{|l|}{ Modic 3} \\
\hline 0 & 99 & 98.3 & \\
\hline 1 & 1 & 1.7 & 0.472 \\
\hline \multicolumn{4}{|l|}{ Smoker } \\
\hline 0 & 80.3 & 80 & \\
\hline 1 & 19.7 & 20 & 0.952 \\
\hline \multicolumn{4}{|l|}{ Gender } \\
\hline 1 & 62 & 55.2 & \\
\hline 2 & 38 & 44.8 & 0.294 \\
\hline VAS back (mean) & 36 & 48 & 0.002 \\
\hline VAS leg (mean) & 64 & 65 & - \\
\hline Mean age (years) & 52 & 53 & - \\
\hline
\end{tabular}

The $p$ value is tested for each variable. For example, the table illustrates that $25.9 \%$ of patients in the DDD group had M1 and that the same result for patients in the non-DDD group was $20.3 \%(p=0.313)$. Gender 1 , male; gender 2 , female.

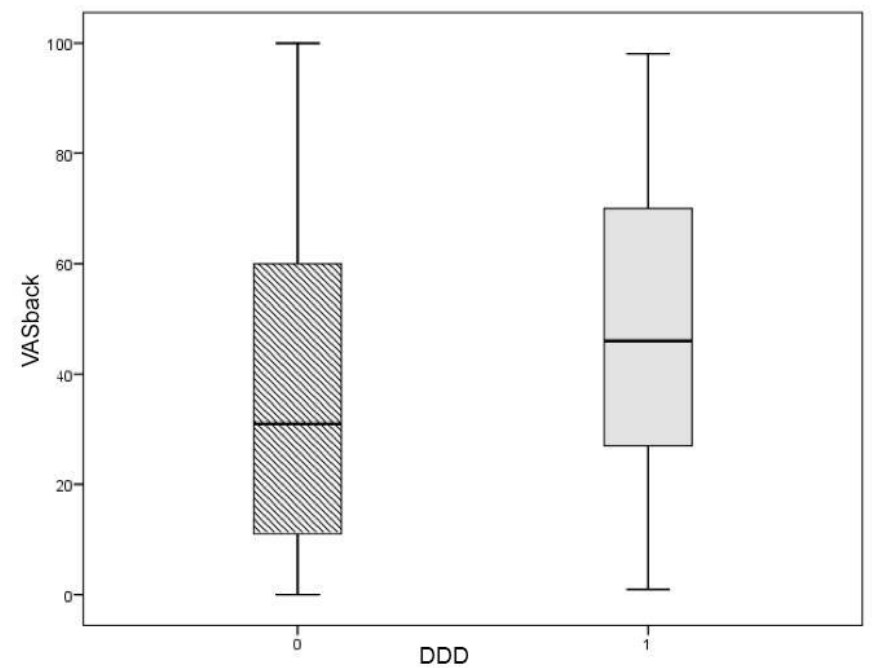

Figure 2. Boxplot illustrating the difference in preoperative VAS back and its normal distribution among patients in the DDD group versus patients in the non-DDD group.

had M1, 46.3\% had M2 and 9.4\% showed M1-2 ( $p=0.000)$. Patients with a markedly reduced disc height (3) were significantly older (median age 56 years), than patients with normal (1) or slightly reduced disc height (2) (both with median age 50 years) $(p=0.003)$ (Tables 5 and 6$)$.

\section{Location of LDH}

In the DDD group, $10.3 \%$ had a medial LDH compared with $10.7 \%$ in the non-DDD group; $84.4 \%$ had a paramedial LDH versus $81.8 \%$ in the non-DDD group; $5.2 \%$ in the DDD group versus $7.4 \%$ in the non-DDD group had a lateral LDH $(p=0.805)$ (Table 7). Patients with lateral LDH (location 3 ) were significantly older (median age 58 years) than patients with paramedial (location 2) (median age 50 years) and especially medial LDH (location 1 ) (median age 47 years) $(p=0.000)$ (Table 7). 
Solmell O (2016) Are there findings on MRI or on patient-reported back pain before surgery for lumbar disc herniation that can predict future progression of painful disc degeneration?

Table 3. Correlations between M1 and DDD and with different variables: gender, smoker, age, VAS back and VAS leg.

Modic 1

\begin{tabular}{|c|c|c|c|c|c|c|c|}
\hline & \multicolumn{2}{|l|}{$\mathbf{0}$} & \multicolumn{2}{|l|}{1} & \multicolumn{3}{|l|}{ Total } \\
\hline & Count & Column $N \%$ & Count & Column $N \%$ & Count & Column $N \%$ & $p$ value \\
\hline \multicolumn{8}{|c|}{ Categorical data } \\
\hline \multicolumn{8}{|l|}{ Gender } \\
\hline 1 & 442 & 65.5 & 86 & 48.9 & 528 & 62 & \\
\hline 2 & 233 & 34.5 & 90 & 51.1 & 323 & 38 & 0 \\
\hline \multicolumn{8}{|l|}{ Smoker } \\
\hline & 554 & 83.2 & 132 & 75 & 686 & 81.5 & \\
\hline 1 & 112 & 16.8 & 44 & 25 & 156 & 18.5 & 0.013 \\
\hline \multicolumn{8}{|l|}{ DDD } \\
\hline 0 & 632 & 93.6 & 161 & 91.5 & 793 & 93.2 & \\
\hline 1 & 43 & 6.4 & 15 & 8.5 & 58 & 6.8 & 0.313 \\
\hline \multicolumn{8}{|c|}{ Numerical data } \\
\hline & Mean/median (SD) & $N$ & Mean/median (SD) & $N$ & Mean/median (SD) & $N$ & \\
\hline Age (years) & $51.0 / 50(11.60)$ & 675 & $51.6 / 50(10.32)$ & 176 & $51.1 / 50(11.34)$ & 851 & - \\
\hline VAS back & $36.6 / 30(28.32)$ & 666 & $38.4 / 35(29.21)$ & 175 & $37.0 / 31(28.50)$ & 841 & - \\
\hline VAS leg & $64.1 / 69(24.32)$ & 667 & $64.4 / 69(24.78)$ & 174 & $64.2 / 69(24.40)$ & 841 & - \\
\hline
\end{tabular}

Table 4. M2 and its possible correlations to gender, smoker, DDD, age, VAS back and VAS leg.

\begin{tabular}{|c|c|c|c|c|c|c|c|}
\hline & \multicolumn{7}{|l|}{ Modic 2} \\
\hline & \multicolumn{2}{|l|}{$\mathbf{0}$} & \multicolumn{2}{|l|}{1} & \multicolumn{3}{|l|}{ Total } \\
\hline & Count & Column $N \%$ & Count & Column $N \%$ & Count & Column $N \%$ & $p$ values \\
\hline \multicolumn{8}{|c|}{ Categorical data } \\
\hline \multicolumn{8}{|l|}{ Gender } \\
\hline 1 & 324 & 62.9 & 204 & 60.7 & 528 & 62 & \\
\hline 2 & 191 & 37.1 & 132 & 39.3 & 323 & 38 & 0.518 \\
\hline \multicolumn{8}{|l|}{ Smoker } \\
\hline 0 & 416 & 81.7 & 270 & 81.1 & 686 & 81.5 & \\
\hline 1 & 93 & 18.3 & 63 & 18.9 & 156 & 18.5 & 0.813 \\
\hline \multicolumn{8}{|l|}{ DDD } \\
\hline 0 & 476 & 92.4 & 317 & 94.3 & 793 & 93.2 & \\
\hline 1 & 39 & 7.6 & 19 & 5.7 & 58 & 6.8 & 0.278 \\
\hline \multicolumn{8}{|c|}{ Numerical data } \\
\hline & Mean/median (SD) & $N$ & Mean/median (SD) & $N$ & Mean/median (SD) & $N$ & \\
\hline Age (years) & 49.7/48 (11.97) & 515 & $53.3 / 52(9.94)$ & 336 & $51.1 / 50(11.34)$ & 851 & 0 \\
\hline VAS back & $38.8 / 34(29.05)$ & 508 & $34.2 / 28(27.44)$ & 333 & $37.0 / 31(28.50)$ & 841 & 0.036 \\
\hline VAS leg & $64.2 / 69(24.59)$ & 508 & $64.1 / 70(24.16)$ & 333 & $64.2 / 69(24.40)$ & 841 & - \\
\hline
\end{tabular}

The calculations were done as in Table 3. Gender 1, male; 2 , female.

Table 5. Correlations between disc height and different variables.

\begin{tabular}{|c|c|c|c|c|c|c|c|c|c|}
\hline & \multicolumn{9}{|c|}{ Disc height (3 categories) } \\
\hline & \multicolumn{2}{|l|}{1} & \multicolumn{2}{|l|}{2} & \multicolumn{2}{|l|}{3} & \multicolumn{3}{|l|}{ Total } \\
\hline & Count & Column $N \%$ & Count & Column $N \%$ & Count & Column $N \%$ & Count & Column $N \%$ & $p$ value \\
\hline \multicolumn{10}{|c|}{ Categorical data } \\
\hline \multicolumn{10}{|l|}{ Gender } \\
\hline 1 & 184 & 63.4 & 316 & 62.8 & 28 & 48.3 & 528 & 62 & \\
\hline 2 & 106 & 36.6 & 187 & 37.2 & 30 & 51.7 & 323 & 38 & 0.08 \\
\hline \multicolumn{10}{|l|}{ Smoker } \\
\hline 0 & 237 & 82.9 & 405 & 81.3 & 44 & 75.9 & 686 & 81.5 & \\
\hline 1 & 49 & 17.1 & 93 & 18.7 & 14 & 24.1 & 156 & 18.5 & 0.453 \\
\hline \multicolumn{10}{|l|}{ DDD } \\
\hline 0 & 272 & 93.8 & 465 & 92.4 & 56 & 96.6 & 793 & 93.2 & \\
\hline 1 & 18 & 6.2 & 38 & 7.6 & 2 & 3.4 & 58 & 6.8 & 0.441 \\
\hline \multicolumn{10}{|c|}{ Numerical data } \\
\hline & Median/mean (SD) & $N$ & Median/mean (SD) & $N$ & Median/mean (SD) & $N$ & Median/mean (SD) & $N$ & \\
\hline Age & 50/51.1 (11.9) & 290 & $50 / 50.6(10.9)$ & 503 & $56 / 55.8(10.8)$ & 58 & $50 / 51.1(11.3)$ & 851 & 0.003 \\
\hline VAS back & $31 / 36.9(28.6)$ & 287 & $31 / 36.3(28.2)$ & 498 & $41 / 43.3(30.1)$ & 56 & $31 / 37.0(28.5)$ & 841 & \\
\hline VAS leg & $71 / 65.5(24.4)$ & 288 & $68 / 63.5(24.1)$ & 497 & $70 / 62.9(26.9)$ & 56 & $69 / 64.2(24.4)$ & 841 & \\
\hline
\end{tabular}

In addition to its association with DDD, connections between disc height and gender, smoking, age, VAS back and VAS leg are shown. Disc height is demonstrated and tested in three categories (1, not reduced height; 2 , slightly reduced; and 3, markedly reduced disc height). Gender 1, male; 2, female. 
Solmell O (2016) Are there findings on MRI or on patient-reported back pain before surgery for lumbar disc herniation that can predict future progression of painful disc degeneration?

Table 6. Disc height categories 2 and 3 considered as one group: group 2.

\begin{tabular}{|c|c|c|c|c|c|c|c|}
\hline & \multicolumn{6}{|c|}{ Disc height (2 categories) } & \multirow[b]{3}{*}{$p$ value } \\
\hline & \multicolumn{2}{|l|}{1} & \multicolumn{2}{|l|}{2} & \multicolumn{2}{|l|}{ Total } & \\
\hline & Count & Column $N \%$ & Count & Column $N \%$ & Count & Column $N \%$ & \\
\hline \multicolumn{8}{|c|}{ Categorical data } \\
\hline \multicolumn{8}{|l|}{ Gender } \\
\hline 1 & 184 & 63.4 & 344 & 61.3 & 528 & 62.0 & \\
\hline 2 & 106 & 36.6 & 217 & 38.7 & 323 & 38.0 & 0.544 \\
\hline \multicolumn{8}{|l|}{ Smoker } \\
\hline 0 & 237 & 82.9 & 449 & 80.8 & 686 & 81.5 & \\
\hline 1 & 49 & 17.1 & 107 & 19.2 & 156 & 18.5 & 0.455 \\
\hline \multicolumn{8}{|l|}{ DDD } \\
\hline 0 & 272 & 93.8 & 521 & 92.9 & 793 & 93.2 & \\
\hline 1 & 18 & 6.2 & 40 & 7.1 & 58 & 6.8 & 0.612 \\
\hline \multicolumn{8}{|c|}{ Numerical data } \\
\hline & Median/mean (SD) & $N$ & Median/mean (SD) & $N$ & Median/mean (SD) & $N$ & \\
\hline VAS back & $31 / 36.9(28.6)$ & 287 & $32 / 37.0(28.5)$ & 554 & $31 / 37.0(28.5)$ & 841 & - \\
\hline VAS leg & $71 / 65.5(24.4)$ & 288 & $68 / 63.5(24.4)$ & 553 & $69 / 64.2(24.4)$ & 841 & - \\
\hline
\end{tabular}

Table 7. Correlations between the location of LDH and the other variables tested.

\begin{tabular}{|c|c|c|c|c|c|c|c|c|c|}
\hline & \multicolumn{8}{|c|}{ Location of LDH } & \multirow[b]{3}{*}{$p$ values } \\
\hline & \multicolumn{2}{|l|}{1} & \multicolumn{2}{|l|}{2} & \multicolumn{2}{|l|}{3} & \multicolumn{2}{|l|}{ Total } & \\
\hline & Count & Column $N \%$ & Count & Column $N \%$ & Count & Column $N \%$ & Count & Column $N \%$ & \\
\hline \multicolumn{10}{|c|}{ Categorical data } \\
\hline \multicolumn{10}{|l|}{ Gender } \\
\hline 1 & 56 & 61.5 & 434 & 62.2 & 38 & 61.3 & 528 & 62.0 & \\
\hline 2 & 35 & 38.5 & 264 & 37.8 & 24 & 38.7 & 323 & 38.0 & 0.985 \\
\hline \multicolumn{10}{|l|}{ Smoker } \\
\hline 0 & 68 & 74.7 & 569 & 82.6 & 49 & 79.0 & 686 & 81.5 & \\
\hline 1 & 23 & 25.3 & 120 & 17.4 & 13 & 21.0 & 156 & 18.5 & 0.169 \\
\hline \multicolumn{10}{|l|}{ DDD } \\
\hline 0 & 85 & 93.4 & 649 & 93.0 & 59 & 95.2 & 793 & 93.2 & \\
\hline 1 & 6 & 6.6 & 49 & 7.0 & 3 & 4.8 & 58 & 6.8 & 0.805 \\
\hline \multicolumn{10}{|c|}{ Numerical data } \\
\hline & $\begin{array}{l}\text { Median/mean } \\
\text { (SD) }\end{array}$ & $N$ & $\begin{array}{l}\text { Median/mean } \\
\text { (SD) }\end{array}$ & $N$ & $\begin{array}{l}\text { Median/mean } \\
\text { (SD) }\end{array}$ & $N$ & $\begin{array}{l}\text { Median/mean } \\
\text { (SD) }\end{array}$ & $N$ & \\
\hline VAS back & $35 / 41.4(29.2)$ & 89 & $31 / 36.6(28.5)$ & 690 & 27/35.0 (27.6) & 62 & $31 / 37.0(28.5)$ & 841 & \\
\hline VAS leg & 73/66.9 (22.3) & 89 & $69 / 63.9(24.5)$ & 690 & 72/63.2 (25.9) & 62 & $69 / 64.2(24.4)$ & 841 & \\
\hline
\end{tabular}

Gender 1, male; 2, female.

\section{Correlation between disc height and location of $\mathrm{LDH}$}

A negative linear association was seen. If the disc height went from a normal level (disc height 1) to a markedly reduced level (disc height 3), the location of the LDH went from lateral (location 3) to medial (location 1).

\section{Logistic regression analyses}

In the univariate regression analysis, the only significant regression model was that including VAS back (Table 8). In the multiple regression analysis, some equations combining different variables were tested. No significant results could be found except for a model including only VAS back (Table 9). In the inter-observer analysis, the kappa score was $90.24 \%$. In the intra-observer analysis, the kappa score was $89.03 \%$.

\section{Discussion}

This study aimed to find predictors that could help us to identify patients, scheduled for LDH surgery that have a higher risk of developing CLBP caused by DDD. Modic changes, disc height and the location of LDH on MR images from 851 patients were analysed. To our knowledge no studies of this kind have been performed previously.

Our results are supported in a recent study that concluded that patients seeking primary care because of LBP, reporting a high baseline level of pain, have a significantly higher risk of CLBP 6 months and 5 years later, respectively, compared with patients who reported lower levels of pain [2].

Although this study did not find any significant correlations between radiologic findings and DDD, some interesting significant associations between Modic changes and VAS for back pain could be seen. We found a non-significant trend that $\mathrm{M} 2$ tends to be less common and M1 more common among patients who develop DDD compared with those who do not. In addition, M2 correlated significantly with a lower score for VAS back pain, whereas M1 seemed to correlate with a higher VAS back [18]. Can the underlying mechanisms that cause M2 be inhibiting for the development of future CLBP caused by DDD? The presence of M2 accompanied by relatively low scores for VAS 
Solmell O (2016) Are there findings on MRI or on patient-reported back pain before surgery for lumbar disc herniation that can predict future progression of painful disc degeneration?

Table 8. Univariate regression analysis

\begin{tabular}{|l|c|c|c|c|c|c|}
\hline & A & B & C & D & E & F \\
\cline { 2 - 7 } & B & Exp (B) & & Sig. & $\begin{array}{c}\mathbf{9 5 \%} \text { CI for } \\
\text { exp (B) }\end{array}$ & $\begin{array}{c}\text { Nagelkerke } \\
\boldsymbol{R}^{\mathbf{2}}\end{array}$ \\
\hline Woman & 0.284 & 1.328 & - & 0.296 & $0.780-2.260$ & 0.003 \\
\hline VAS back & 0.014 & 1.014 & 1.150 & 0.002 & $1.005-1.024$ & 0.025 \\
\hline Smoker: yes & 0.021 & 1.021 & - & 0.952 & $0.519-2.010$ & 0.000 \\
\hline Age & 0.005 & 1.005 & 1.051 & 0.675 & $0.983-1.027$ & 0.000 \\
\hline Modic 1: yes & 0.314 & 1.369 & - & 0.315 & $0.742-2.527$ & 0.003 \\
\hline Modic 2: yes & -0.313 & 0.732 & - & 0.279 & $0.415-1.289$ & 0.004 \\
\hline Modic 3: yes & 0.543 & 1.721 & - & 0.612 & $0.212-14.004$ & 0.001 \\
\hline Disc height: reduced & 0.149 & 1.160 & - & 0.613 & $0.653-2.062$ & 0.001 \\
\hline Location of LDH: 2 (vs. 1) & 0.067 & 1.070 & - & 0.881 & $0.445-2.572$ & 0.001 \\
\hline Location of LDH: 3 (vs. 1) & -0.328 & 0.720 & - & 0.652 & $0.173-2.995$ & 0.001 \\
\hline Modic (1) (of any kind) & -0.055 & 0.947 & - & 0.841 & $0.555-1.614$ & 0.000 \\
\hline
\end{tabular}

Each variable has been tested and calculated against the possible development of DDD. A: The estimated influence for the specific variable; B: Odds ratio for DDD, in other words the odds for DDD when the variable increases one step; C: Differences in odds ratio when the variable increases 10 steps (only numerical variables); $\mathrm{D}$, the significance for the estimation ( $p$ value); E, 95\% confidence interval for the estimated odds ratio; F, the Nagelkerke $R^{2}$ value for the model, i.e., how much of the variation in DDD can be explained by the specific variable. For example, VAS back explained $2.5 \%$ of the variation in DDD.

Table 9. Multivariate logistic regression analysis.

\begin{tabular}{|l|l|l|l|l|l|}
\hline Step 1 & B & Significance & Exp(B) & \multicolumn{2}{|l|}{$\mathbf{9 5 \%}$ CI for exp(B) } \\
\hline Woman & & & & Lower & Upper \\
\hline Age & 0.181 & 0.526 & 1.199 & 0.685 & 2.098 \\
\hline Modic 1 & 0.016 & 0.189 & 1.016 & 0.992 & 1.040 \\
\hline Modic 2 & 0.265 & 0.407 & 1.304 & 0.696 & 2.442 \\
\hline VAS back & -0.275 & 0.352 & 0.760 & 0.426 & 1.355 \\
\hline Constant & 0.014 & 0.005 & 1.014 & 1.004 & 1.023 \\
\hline Model summary & -4.047 & 0.000 & 0.017 & & \\
\hline -2 log likelihood & $404.159^{\mathrm{a}}$ & & & & \\
\hline Cox \& Snell $R^{2}$ & 0.015 & & & & \\
\hline Nagelkerke $R^{2}$ & 0.038 & & & & \\
\hline
\end{tabular}

The odds ratio and its significance were calculated for each variable. The model summary tests how much of the variation in DDD can be explained by the combination of the chosen variables $\left(R^{2}\right.$ value). Nagelkerke $R^{2}$ for this model was $0.038(3,8 \%)$.

Variables entered on step 1, gender (female), age, M1, M2, VAS back; variables entered on step 2, gender (female), age, VAS back, smoker and Modic of any kind; variables entered on step 3, Modic change of any kind and medial or paramedial LDH; variables entered on step 4, Modic of any kind and reduced (slightly or markedly) disc height.

back may indicate stagnation of the degenerative process, and possibly mechanical stabilization of the degenerating disc. Some support is found in a study on the evolution of Modic changes [20]. Earlier studies $[19,24]$ proposed that M1 is a sign of accelerated DD, which is often linked to higher scores for VAS back pain. Our significant results concerning M1 and decreased disc height correspond to these propositions. The correlation between M1 and DDD is interesting but not yet conclusive. In this study, we also saw a significant association between disc height and the location of LDH. Patients with a medial LDH more often had reduced disc height compared with patients with lateral LDH. In addition, patients with medial LDH were significantly younger than patients with lateral LDH. In other words, patients with a medial LDH might have more severe DD at an earlier point in life. A twin study from 1991 showed that smokers are at greater risk for developing accelerated DD than non-smokers [11]. We found almost no difference between smokers and non-smokers regarding the development of DDD. On the other hand, we found that M1 occurred significantly more often among smokers than non-smokers, and M1 correlated significantly to decreased disc height, considered by many to be a sign of DD [12,19]. Therefore smoking and M1 seem to have a logical connection to DDD. A potential weakness of this study is the relatively small group that developed such severe symptoms of DDD that surgery was indicated, and possibly partly explains why we found so few statistically significant results. The initial large number of patients (1154) can be considered a strength of the study. Other strengths were that a specialist in neuroradiology guided the radiologic study and kappa scores of $90 \%$ were found in the inter- and intraobserver analyses.

\section{Conclusions}

This study shows a significant correlation between M2, seen on MRI before surgery for LDH, and a low score at VAS back. These findings might be useful as negative predictors for future development of CLBP caused by DDD. Patients who develop CLBP as a result of DDD also have a significantly higher score for VAS back pain before surgery for LDH compared with patients who do not develop DDD. We also found a significant correlation between $\mathrm{M} 1$ and reduced disc height, which indicates a potential correlation between M1 and the development of DDD.

\section{Conflicts of interest}

None of the authors have any conflict of interests.

\section{References}

1. Karunanayake AL, Pathmeswaran A, Kasturiratne A, Wijeyaratne LS (2013) Risk factors for chronic low back pain in a sample of suburban Sri Lankan adult males. Int $J$ Rheum Dis 16: 203-210. [Crossref]

2. Campbell P, Foster NE, Thomas E, Dunn KM (2013) Prognostic indicators of low back pain in primary care: five-year prospective study. J Pain 14: 873-883. [Crossref]

3. Grotle M, Brox JI, Veierød MB, Glomsrød B, Lønn JH, et al. (2005) Clinical course and prognostic factors in acute low back pain: patients consulting primary care for the first time. Spine (Phila Pa 1976) 30: 976-982. [Crossref]

4. Gregg CD, McIntosh G, Hall H, Hoffman CW (2014) Prognostic factors associated with low back pain outcomes. J Prim Health Care 6: 23-30.[Crossref]

5. da C Menezes Costa L, Maher CG, Hancock MJ, McAuley JH, Herbert RD, et al (2012) The prognosis of acute and persistent low-back pain: a meta-analysis. Cmaj 184: 613-624. [Crossref]

6. Cats-Baril WL, Frymoyer JW (1991) Identifying patients at risk of becoming disabled because of low-back pain. The Vermont Rehabilitation Engineering Center predictive model. Spine (Phila Pa 1976) 16: 605-607. [Crossref]

7. Battié MC, Videman T, Levälahti E, Gill K, Kaprio J (2008) Genetic and environmental effects on disc degeneration by phenotype and spinal level: a multivariate twin study. Spine (Phila Pa 1976) 33: 2801-2808. [Crossref]

8. Brisby H (2006) Pathology and possible mechanisms of nervous system response to disc degeneration. J Bone Joint Surg Am 88: 68-71. [Crossref]

9. Benoist M (2003) Natural history of the aging spine. Eur Spine J 12: 86-89. [Crossref]

10. Battié MC, Videman T, Gibbons LE, Fisher LD, Manninen H, et al. (1995) 1995 Volvo Award in clinical sciences. Determinants of lumbar disc degeneration. A study relating lifetime exposures and magnetic resonance imaging findings in identical twins. Spine (Phila Pa 1976) 20: 2601-2612. [Crossref]

11. Battié MC, Videman T, Gill K, Moneta GB, Nyman R, et al. (1991) 1991 Volvo Award in clinical sciences. Smoking and lumbar intervertebral disc degeneration: an MRI study of identical twins. Spine (Phila Pa 1976) 16: 1015-1021. [Crossref]

12. Modic MT, Ross S (2007) Lumbar degenerative disk disease. Radiology 245: 43-61. [Crossref]

13. Peng B, Hao J, Hou S, Wu W, Jiang D, et al. (2006) Possible pathogenesis of painful intervertebral disc degeneration. Spine (Phila Pa 1976) 31: 560-566. [Crossref]

14. Matsui H, Kanamori M, Ishihara H, Yudoh K, Naruse Y, et al. (1998) Familial predisposition for lumbar degenerative disc disease. A case-control study. Spine (Phila 
Solmell O (2016) Are there findings on MRI or on patient-reported back pain before surgery for lumbar disc herniation that can predict future progression of painful disc degeneration?

\section{Pa 1976) 23: 1029-1034. [Crossref]}

15. Modic MT, Masaryk TJ, Ross JS, Carter JR (1988) Imaging of degenerative disk disease. Radiology 168: 177-186. [Crossref]

16. Modic MT, Steinberg PM, Ross JS, Masaryk TJ, Carter JR (1988) Degenerative disk disease: assessment of changes in vertebral body marrow with MR imaging. Radiology 166: 193-199. [Crossref]

17. Albert HB, Kjaer P, Jensen TS, Sorensen JS, Bendix T, et al. (2008) Modic changes, possible causes and relation to low back pain. Med Hypotheses 70: 361-368. [Crossref]

18. Mok FP, Samartzis D, Karppinen J, Fong DY, Luk KD, et al. (2016) Modic changes of the lumbar spine: prevalence, risk factors, and association with disc degeneration and low back pain in a large-scale population-based cohort. Spine $J$ 16: 32-41. [Crossref]

19. Kerttula L, Luoma K, Vehmas T, Grönblad M, Kääpä E (2012) Modic type I change may predict rapid progressive, deforming disc degeneration: a prospective 1-year follow-up study. Eur Spine J 21: 1135-1142.

20. Schistad EI, Espeland A, Rygh LJ, Røe C, Gjerstad J (2014) The association between
Modic changes and pain during 1-year follow-up in patients with lumbar radicular pain. Skeletal Radiol 43: 1271-1279. [Crossref]

21. Steffens D, Hancock MJ, Maher CG, Williams C, Jensen TS (2013) Does magnetic resonance imaging predicts future low back pain? A systematic review. Eur J Pain 18: 755-765. [Crossref]

22. Frobin W, Brinckmann P, Biggemann M, Tillotson M, Burton K (1997) Precision measurement of disc height, vertebral height and sagittal plane displacement from lateral radiographic views of the lumbar spine. Clin Biomech (Bristol, Avon)12: 1-63. [Crossref]

23. Frobin W, Brinckmann P, Kramer M, Hartwig E (2001) Height of lumbar discs measured from radiographs compared with degeneration and height classified from MR images. Eur Radiol 11: 263-269. [Crossref]

24. Luoma K, Vehmas T, Grönblad M, Kerttula L, Kääpä E (2009) Relationship of Modic type 1 change with disc degeneration: a prospective MRI study. Skeletal Radiol 38 : 237-244. [Crossref]

Copyright: $(02016$ Solmell O. This is an open-access article distributed under the terms of the Creative Commons Attribution License, which permits unrestricted use, distribution, and reproduction in any medium, provided the original author and source are credited. 